\title{
Article \\ Super-Dispersed Fe-N Sites Embedded into Porous Graphitic Carbon for ORR: Size, Composition and Activity Control
}

\author{
Xin Yu Wang ${ }^{1}$, Ze Wei Lin ${ }^{2}$, Yan Qing Jiao ${ }^{1}$, Jian Cong Liu ${ }^{1, *}$ and Rui Hong Wang ${ }^{1, *}$ (D) \\ 1 Key Laboratory of Functional Inorganic Material Chemistry, Ministry of Education, School of Chemistry and \\ Material Science, Heilongiiang University, Harbin 150080, China; wangxinyu11222021@163.com (X.Y.W.); \\ jiaoyanqing@hlju.edu.cn (Y.Q.J.) \\ 2 School of Chemical Engineering and Chemistry, Harbin Institute of Technology, Harbin 150001, China; \\ lzw305145514@163.com \\ * Correspondence: liujiancong@hlju.edu.cn (J.C.L.); wangruihong@hlju.edu.cn (R.H.W.); \\ Tel.: +86-0451-86604331 (J.C.L. \& R.H.W.)
}

check for updates

Citation: Wang, X.Y.; Lin, Z.W.; Jiao, Y.Q.; Liu, J.C.; Wang, R.H. Super-Dispersed Fe-N Sites

Embedded into Porous Graphitic Carbon for ORR: Size, Composition and Activity Control. Nanomaterials 2021, 11, 2106. https://doi.org/ 10.3390/nano11082106

Academic Editors: Raphaël Schneider and Nikos Tagmatarchis

Received: 5 July 2021

Accepted: 17 August 2021

Published: 19 August 2021

Publisher's Note: MDPI stays neutral with regard to jurisdictional claims in published maps and institutional affiliations.

\begin{abstract}
Searching for high-efficient, good long-term stability, and low-cost electrocatalysts toward oxygen reduction reaction (ORR) is highly desirable for the development of sustainable energy conversion devices. Iron-nitrogen doped carbon $(\mathrm{Fe}-\mathrm{N} / \mathrm{C})$ catalysts have been recognized as the most promising candidates for traditional Pt-based catalysts that benefit from their high activity, excellent anti-poisoning ability, and inexpensiveness. Here, a super-dispersed and high-performance $\mathrm{Fe}-\mathrm{N} / \mathrm{C}$ catalyst was derived from chemically Fe-doped zeolitic imidazolate frameworks (ZIFs) by directly bonding Fe ions to imidazolate ligands within 3D frameworks. It produced a series of catalysts, whose sizes could be tuned in the range from 62 to over $473 \mathrm{~nm}$ in diameter. After rationally regulating the component and heating treatment, the best ORR activity was measured for the catalyst with a size of $105 \mathrm{~nm}$, which was obtained when the $\mathrm{Fe}^{3+} / \mathrm{Zn}^{2+}$ molar ratio was 0.05 and carbonization temperature was $900{ }^{\circ} \mathrm{C}$. It exhibited a high onset potential $\left(\mathrm{E}_{\text {onset }}=0.99 \mathrm{~V}\right)$ and half-wave potential $\left(\mathrm{E}_{1 / 2}=0.885 \mathrm{~V}\right)$ compared with a commercial $20 \% \mathrm{Pt} / \mathrm{C}$ catalyst $\left(\mathrm{E}_{\text {onset }}=0.10 \mathrm{~V}\right.$, $\mathrm{E}_{1 / 2}=0.861 \mathrm{~V}$ ) as well as much better durability and methanol resistance in an alkaline electrolyte.
\end{abstract}

Keywords: Fe-N sites; ZIF-8; super-dispersion; ORR; high catalytic performance

\section{Introduction}

The oxygen reduction reaction (ORR) is one of the crucial electrochemical processes for clean energy devices such as fuel cells [1,2] and metal-air batteries [3-5]. However, a large amount of $\mathrm{Pt}$ is required to catalyze the kinetically sluggish ORR at the cathode, which therefore severely restricts their widespread commercialization [6,7]. Employment of high-performance, non-precious metal ORR catalysts is considered as a long-term goal for the evolution of these technologies.

Recently, the coordinately unsaturated transition metal-nitrogen sites confined within the carbon matrix have been widely explored as efficient and promising non-precious metal catalysts that many hope may be able to replace Pt-based catalysts toward ORR [8-11]. To date, $\mathrm{Fe}-\mathrm{N} / \mathrm{C}$ catalysts are one of the most brilliant candidates due to their excellent ORR activity, stability, and instinctive anti-poisoning power [12-17]. Combining the theoretical calculations with the experimental results, the co-doping of $\mathrm{Fe}$ and $\mathrm{N}$ in the form of iron-nitrogen $(\mathrm{Fe}-\mathrm{N})$ is considered to provide active sites for $\mathrm{O}_{2}$ adsorption and the subsequent breaking of $\mathrm{O}=\mathrm{O}$ bonding in $\mathrm{ORR}[18,19]$. Hence, many efforts have been devoted to increasing the Fe-N site with the carbon matrix, which have led to encouraging performance improvement. However, undesirable aggregation of metal atoms is prone to forming during high-temperature pyrolysis with increasing metal content, which leads to a decline in catalytic activity $[20,21]$. Therefore, it is highly desirable to explore the super- 
dispersed, especially the atomically-dispersed $\mathrm{Fe}-\mathrm{N}$ sites, at a high density embedded into a favorable carbon matrix.

Metal-organic frameworks (MOFs), constructed from central metal ions and ligands, have attracted tremendous attention as precursors for the synthesis of non-precious metal catalysts [22-27]. MOF-derived catalyst materials can not only inherit their parents' morphology, but also contain all the necessary elements (metal, carbon, and nitrogen) as well as tunable chemical composition. More recently, the zinc-based zeolite imidazole framework (ZIF-8) has been widely studied to encapsulate organic [28,29] or inorganic [30-32] ironcontaining molecules, which were then subjected to pyrolysis at high temperature under an inert gas to prepare the $\mathrm{Fe}-\mathrm{N}-\mathrm{C}$ catalysts. Due to the uniform dispersion of Fe species in precursors, the obtained catalyst possesses the high-dispersed Fe-N sites confined within the carbon matrix. Although these studies have made significant achievements in ORR electrocatalytic activity, there is still room for improvement. Meanwhile, the particle size and distribution play an important role in the ORR performance; however, the detailed investigation of the structure-performance correlations is limited.

In this work, a series of Fe-doped ZIF precursors with different $\mathrm{Fe}^{3+} / \mathrm{Zn}^{2+}$ molar ratios were easily synthesized through a chemical doping approach. In this process, the Fe ions could partially replace $\mathrm{Zn}$ ions and coordinate with imidazole ligands, which enable them to be highly dispersed in the organic skeleton. After one-step pyrolysis, porous carbon with a hierarchical structure was obtained, in which the Fe in the form of Fe-N were super-dispersed at an atomic scale. The size of the catalyst is tunable over a wide range from 62 to $473 \mathrm{~nm}$, which can be tailored by rationally regulating the component and heating treatment. More attention was paid to the structure-performance correlations; as a result, the best optimized ORR activity was achieved on a catalyst of $105 \mathrm{~nm}$, which exhibited a half-wave potential of $0.885 \mathrm{~V}$, limit current of $4.8 \mathrm{~mA} \mathrm{~cm}^{-2}$, and better long-time durability than the commercial $20 \% \mathrm{Pt} / \mathrm{C}$ catalyst.

\section{Materials and Methods}

\subsection{Synthesis of Fe-ZIF Precursors}

A wide range of crystal sizes of Fe-doped ZIF was controlled by tuning the molar ratios of $\mathrm{Fe}\left(\mathrm{NO}_{3}\right)_{3} \cdot 9 \mathrm{H}_{2} \mathrm{O}$ and $\mathrm{Zn}\left(\mathrm{NO}_{3}\right)_{2} \cdot 6 \mathrm{H}_{2} \mathrm{O}$ to $0.025: 1,0.05: 1$, and $0.075: 1$. Typically, in the case of a Fe ${ }^{3+} / \mathrm{Zn}^{2+}$ molar ratio of $0.05: 1,1 \mathrm{mmol} \mathrm{Zn}\left(\mathrm{NO}_{3}\right)_{2} \cdot 6 \mathrm{H}_{2} \mathrm{O}(297 \mathrm{mg})$ and $0.05 \mathrm{mmol}$ $\mathrm{Fe}\left(\mathrm{NO}_{3}\right)_{3} \cdot 9 \mathrm{H}_{2} \mathrm{O}(20 \mathrm{mg})$ are dissolved in $40 \mathrm{~mL}$ methanol and stirred to form a clear solution. This solution was subsequently poured into another clear solution containing $328 \mathrm{mg}$ of 2-methylimidazole dissolved in $40 \mathrm{~mL}$ of methanol. Then, the mixed solution was heated at $100^{\circ} \mathrm{C}$ for $12 \mathrm{~h}$. After cooling to room temperature, the product was collected via centrifugation and washed with methanol several times. After drying at $60{ }^{\circ} \mathrm{C}$ under a vacuum overnight, a precursor named Fe-ZIF-0.05 was obtained. Similarly, the Fe-ZIF precursors with $\mathrm{Fe}^{3+} / \mathrm{Zn}^{2+}$ molar ratios of $0.025: 1$ and $0.075: 1$ were also synthesized based on the same process and named as Fe-ZIF-0.025 and Fe-ZIF-0.075, respectively.

\subsection{Synthesis of $\mathrm{Fe}-\mathrm{N} / \mathrm{C}$ Catalyst}

First, Fe-ZIF precursors with different $\mathrm{Fe}^{3+} / \mathrm{Zn}^{2+}$ molar ratios were carbonized at $900{ }^{\circ} \mathrm{C}$ in $\mathrm{N}_{2}$ with a heating rate of $5^{\circ} \mathrm{C} \mathrm{min}^{-1}$ to achieve pyrolysis and graphitization. After cooling to room temperature, the black powder was put into $100 \mathrm{~mL} 0.5 \mathrm{M} \mathrm{H}_{2} \mathrm{SO}_{4}$ solution and heated at $80^{\circ} \mathrm{C}$ for $10 \mathrm{~h}$ to etch the unstable inorganic metal phase. In the end, the final catalysts of Fe-N/C (Fe-N/C-0.025-900), Fe-N/C-0.05-900, and Fe-N/C-0.075900) were obtained after centrifugation and separation. In order to explore the effect of heat treatment temperature on the morphology and activity, the Fe-ZIF-0.05 precursor was processed at different temperatures $\left(600-1000^{\circ} \mathrm{C}\right)$ by the same method, and the products were denoted as Fe-N/C-0.05-600, Fe-N/C-0.05-700, Fe-N/C-0.05-800, Fe-N/C-0.05-900, and $\mathrm{Fe}-\mathrm{N} / \mathrm{C}-0.05-1000$, respectively. 


\subsection{Material Characterization}

X-ray diffraction (XRD) patterns were performed with an X-ray diffractometer (XRD, Bruker D8 Advanced) with an accelerating voltage of $40 \mathrm{kV}$. The Raman data were collected using a Raman spectrometer (Jobin Yvon HR800). The morphologies of the synthesized samples were studied by SEM (Philips XL-30-ESEM-FEG, 5-20 kV). The Brunauer-EmmettTeller (BET) surface area of the product was measured by using $\mathrm{N}_{2}$ adsorption/desorption (TriStar II 3020). Transmission electron microscopy (TEM), high-resolution TEM (HRTEM), dark-field scanning transmission electron microscopy (STEM), and energy-dispersive Xray measurement (EDX) were implemented on TEM JEOL JEM-3010. The chemical state and surface composition were investigated by the X-ray photoelectron spectroscopy (XPS, VG ESCALAB MK II). The surface area and average pore width were measured on a Micromeritics TrisStar II 3020.

\subsection{Electrochemical Measurements}

Electrochemical properties were tested using a Pine electrochemical workstation by a standard three-electrode system at room temperature, in which a rotating ring-disk electrode (RRDE, area $=0.2470 \mathrm{~cm}^{2}$ ) was used as the working electrode and a Pt flake and reversible hydrogen electrode (RHE) were adopted as the counter and reference electrodes, respectively. The catalyst ink was prepared by ultrasonically dispersing a mixture containing $5 \mathrm{mg}$ of catalyst, $0.8 \mathrm{~mL}$ of isopropyl alcohol, $0.2 \mathrm{~mL}$ of deionized water, and $30 \mu \mathrm{L}$ of Nafion ( $5 \mathrm{wt} \%$ ). Subsequently, $30 \mathrm{~mL}$ of the catalyst ink was pipetted onto a pre-cleaned working electrode. The ORR performance was recorded at $1600 \mathrm{rpm}$ with a scan rate of $5 \mathrm{mV} \mathrm{s}^{-1}$ in $\mathrm{O}_{2}$-saturated $0.1 \mathrm{M} \mathrm{KOH}$ at room temperature, and the potentials are given versus a reversible hydrogen electrode (vs. RHE). The loading amount on RRDE was $0.589 \mathrm{mg} \mathrm{cm}^{-2}$, and the potential range was controlled in the range of $0-1.2 \mathrm{~V}$ for all measurements. Chronoamperometry (CA) was performed to assess the durability and methanol tolerance for catalysts under $0.885 \mathrm{~V}$ for $10,000 \mathrm{~s}$ with a rotating speed of $1600 \mathrm{rpm}$.

\section{Results}

\subsection{Structural Characterization of Fe-N/C Catalyst}

Figure 1a displays the XRD patterns of the pure ZIF-8 and Fe-ZIF precursors with different $\mathrm{Fe}^{3+} / \mathrm{Zn}^{2+}$ molar ratios. All of the samples exhibited the characteristic peaks at $7.38^{\circ}, 10.42^{\circ}, 12.77^{\circ}, 14.75^{\circ}, 16.50^{\circ}$, and $18.08^{\circ}$, which are ascribable to the (101), (002), (112), (200), (013), and (222) planes of ZIF-8, respectively [33]. These results demonstrate that the Fe-ZIF precursors inherited the original structure from pure ZIF-8, and that the introduction of low-concentration $\mathrm{Fe}^{3+}$ did not change the structure of the ZIF-8 framework. Despite no shift in the diffraction peak being observable with the increasing molar ratios of $\mathrm{Fe}^{3+} / \mathrm{Zn}^{2+}$, the peak intensity was significantly enhanced, indicating the improved crystallinity of Fe-ZIF precursors. Subsequently, all the precursors including the pure ZIF-8 were carbonized at $900{ }^{\circ} \mathrm{C}$ in a $\mathrm{N}_{2}$ atmosphere. The XRD patterns of products after carbonation are exhibited in Figure 1b, where the wide peaks between $2 \theta$ of 20 and $30^{\circ}$ are typical characteristics of carbon material derived from ZIF-8 [34].

Raman spectroscopy was adopted to further reveal the crystallinity of carbon. As displayed in Figure 1c, two distinct peaks at 1588.24 and $1359.91 \mathrm{~cm}^{-1}$ can be ascribable to the G-band and D-band of graphite, respectively, corresponding to the $\mathrm{sp}^{2}$ bonds of graphitic structure and the $\mathrm{sp}^{3}$ bonds of defects in the carbon matrix $[35,36]$. The $\mathrm{I}_{G} / \mathrm{I}_{\mathrm{D}}$ value represents the ratio of the degree of defect density and the degree of graphitization of materials [36,37]. For the pure carbon derived from ZIF-8, the intensity ratio of G-band to D-band $\left(\mathrm{I}_{\mathrm{G}} / \mathrm{I}_{\mathrm{D}}\right)$ was 1.168 , which proves that the product was graphited due to the catalytic effect of the transition metal at a high temperature. For the carbon materials obtained from Fe-ZIF precursors, the $\mathrm{I}_{\mathrm{G}} / \mathrm{I}_{\mathrm{D}}$ values were $1.184,1.162$ and 1.159 , indicating that the graphitization of carbon was improved with increased iron content. 

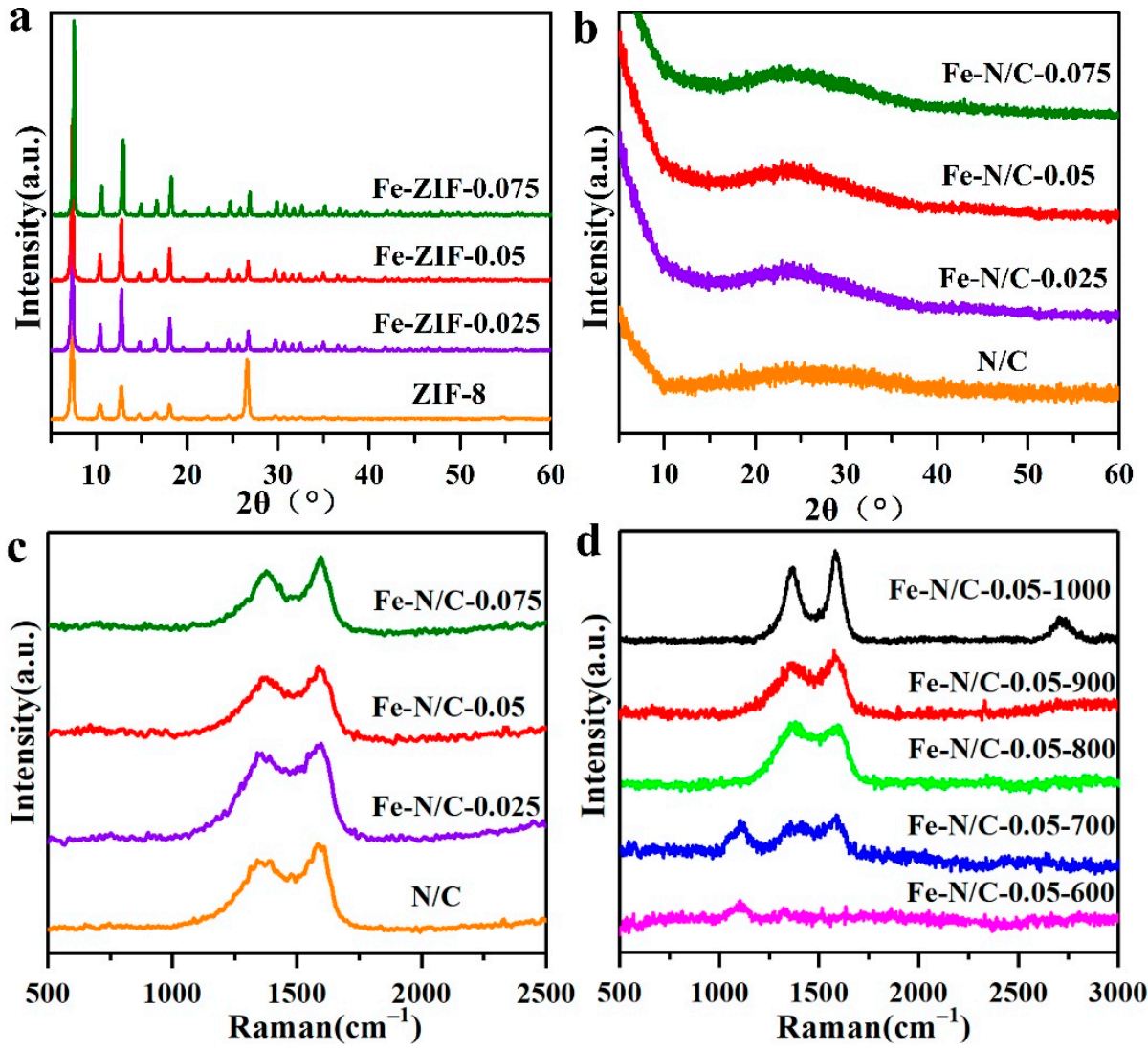

Figure 1. (a) The XRD patterns of the precursors with different Fe feeding, (b) XRD patterns, (c) Raman spectra of products synthesized under $900{ }^{\circ} \mathrm{C}$, and (d) Raman spectra of products by carbonizing Fe-ZIF-0.05 precursors at different temperatures.

To further investigate the effect of carbonization temperatures on the degree of graphitization (Figure 1d), the Fe-ZIF-0.05 precursor was treated at different temperatures $\left(600-1000{ }^{\circ} \mathrm{C}\right)$. At a temperature of $600{ }^{\circ} \mathrm{C}$, the Raman band at $1115 \mathrm{~cm}^{-1}$ is a typical characteristic spectra for Fe-zeolite imidazole skeleton [38]. When the temperature was up to $700{ }^{\circ} \mathrm{C}$, the Raman peaks of G-band and D-band appeared, respectively. As the temperature increased to $800^{\circ} \mathrm{C}$, the Raman peak corresponding to Fe-ZIF8 disappeared, indicating the complete disintegration of the imidazole skeleton at $800{ }^{\circ} \mathrm{C}$ and the $\mathrm{I}_{\mathrm{G}} / \mathrm{I}_{\mathrm{D}}$ value was calculated to be 1.159 . Upon further increasing the temperature to $900{ }^{\circ} \mathrm{C}$, the $\mathrm{I}_{\mathrm{G}} / \mathrm{I}_{\mathrm{D}}$ value was calculated as 1.162 , corresponding to a typical graphitic carbon [39]. The graphitization was further improved with the increased temperature, and an obvious 2D peak was found at $1000^{\circ} \mathrm{C}$. These results show that a high temperature is beneficial to the formation of graphitization.

Next, the morphology and structural characteristics of Fe-ZIF precursors with different $\mathrm{Fe}^{3+} / \mathrm{Zn}^{2+}$ molar ratios and their products after carbonation at $900{ }^{\circ} \mathrm{C}$ were investigated through SEM. As shown in Figure $2 \mathrm{a}-\mathrm{c}$, all the Fe-ZIF precursors displayed the typical dodecahedron structure of ZIF-8, and evenly in a uniform distribution without significant aggregation. The size of precursors was tunable over a wide range by changing the concentration of metal salts and ligands. For the Fe-ZIF-0.025 sample, the precursor size was $90 \mathrm{~nm}$, which increased with the increase in iron content and reached 200 and $900 \mathrm{~nm}$, respectively, for Fe-ZIF-0.05 and Fe-ZIF-0.075. Figure 2d-f exhibits the SEM images of the carbonized products at $900{ }^{\circ} \mathrm{C}$. It is evident that the products have inherited the main morphology of Fe-ZIF precursors. Due to the dehydration and pyrolysis of organic ligands, the dodecahedral structure collapsed toward the center, resulting in a gradual decrease in size. The average size of products is 62, 105, and $473 \mathrm{~nm}$ for Fe-N/C $-0.025-900$, $\mathrm{Fe}-\mathrm{N} / \mathrm{C}-0.05-900$, and Fe-N/C-0.075-900, respectively. Moreover, the Zn atoms in the 
ZIF structure was easily evaporated $\left(>907^{\circ} \mathrm{C}\right)$, resulting in the porous carbon structures in the products [40]. As can be observed directly from Figure 2d-f, the surface roughness was improved with the increase in $\mathrm{Fe}^{3+} / \mathrm{Zn}^{2+}$ molar ratios.
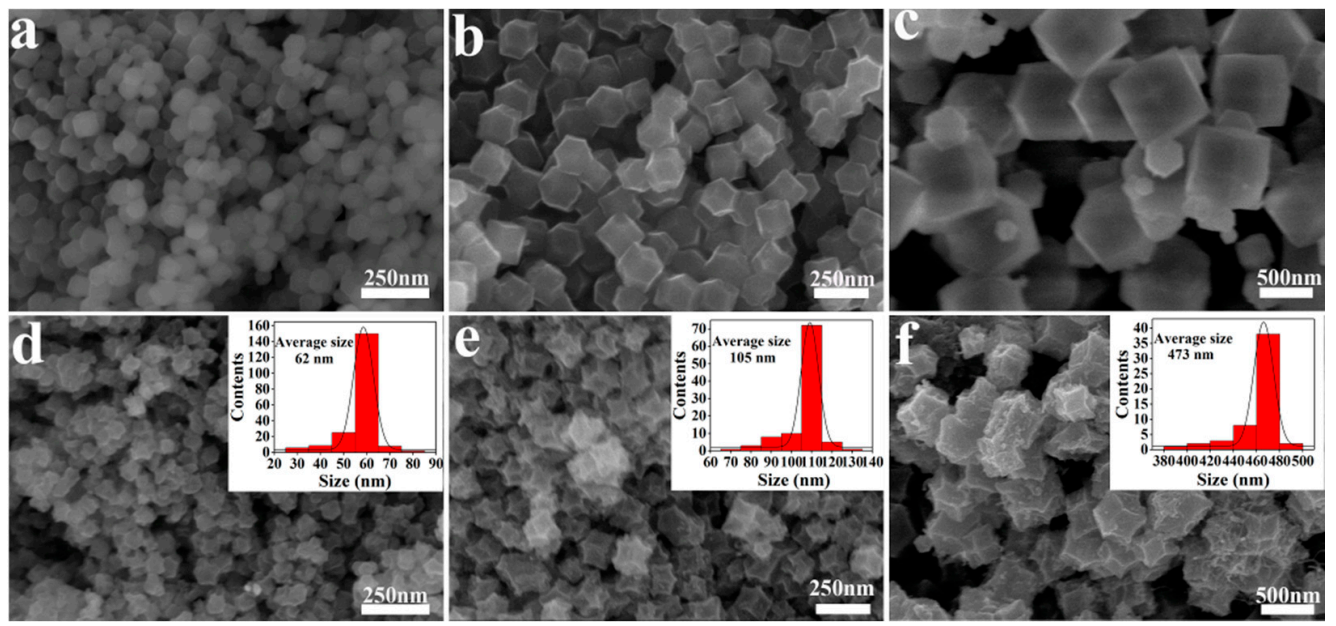

Figure 2. The SEM images of precursors (a) Fe-ZIF-0.025, (b) Fe-ZIF-0.05, (c) Fe-ZIF-0.075 and their carbonized products at $900{ }^{\circ} \mathrm{C}$, (d) Fe-N/C-0.025-900, (e) Fe-N/C-0.05-900, and (f) Fe-N/C-0.075-900.

$\mathrm{N}_{2}$ adsorption/desorption isotherms were measured to evaluate the trends of porosity change with different $\mathrm{Fe}^{3+} / \mathrm{Zn}^{2+}$ molar ratios. As presented in Figure 3, the nitrogen uptake for all samples exhibited the typical Type-I isotherm at the low relative pressure, demonstrating the existence of a microporous structure. At higher relative pressure, a significant hysteresis of the adsorption/desorption process is clearly noticeable, which is indicative of the Type-IV isotherm for mesoporous materials [30]. The porous structure partly originates from the abundant micropores in ZIF-8; moreover, the subsequent vapor of metal $\mathrm{Zn}$ above its boiling point $\left(>907^{\circ} \mathrm{C}\right)$ would also leave it porous in the carbon skeleton. Table 1 gives the detailed trend of the Brunauer-Emmett-Teller (BET) surface area and total pore volume change with the increasing $\mathrm{Fe}^{3+} / \mathrm{Zn}^{2+}$ molar ratios. It was found that the total pore volume gradually decreased with increasing iron concentration. This phenomenon is due to the increase in iron content, which would reduce the inter-particle space available and lower their surface-to-volume ratio. On the other hand, graphitization and specific surface area are contradictory. In other words, the higher the iron content, the more conductivity to improve the electron transfer in ORR; however, this comes with the loss of the specific surface area. Therefore, the surface area, pore structure, and graphitization degree of the product can be controlled by adjusting the iron content. As summarized in Table 1, Fe-N/C-0.05-900 displayed the surface area and total pore volume of $812.1 \mathrm{~m}^{2}$ $\mathrm{g}^{-1}$ and $1.105 \mathrm{~cm}^{3} \mathrm{~g}^{-1}$, respectively, which was medium among all the samples. Such a large specific surface area structure can greatly increase the number of exposed active sites, and the hierarchical micro/meso-porous structure would simultaneously boost the electrochemical activation and mass-transport properties. Hence, we elucidated that the Fe-N/C-0.05-900 sample would be a good potential ORR electrocatalyst. The effect of heating treatment temperature on product size was also investigated on the $\mathrm{Fe}-\mathrm{N} / \mathrm{C}-0.05$ precursor (Figure S1). The average size was 181, 159, 136, 105 and $90 \mathrm{~nm}$, for 600, 700, 800, 900 and $1000{ }^{\circ} \mathrm{C}$, respectively. Therefore, it can be concluded that rising temperature causes the dodecahedron structure to collapse gradually. The influence of catalyst size on ORR activity is also discussed in detail in the performance section. 

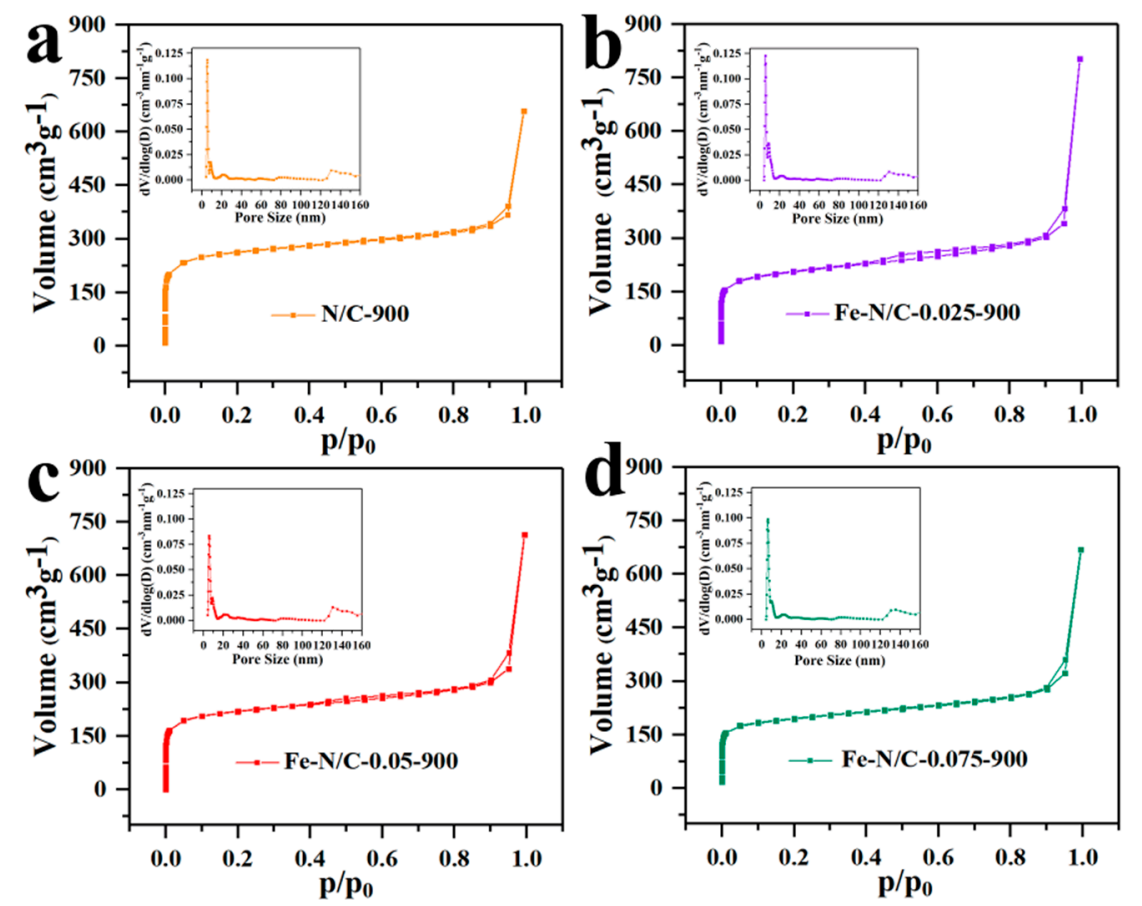

Figure 3. $\mathrm{N}_{2}$ adsorption and desorption isotherms and pore-size distributions of Fe-N/C-900 with different moral ration of iron.

Table 1. BET surface areas and total pore volumes of the as-prepared samples.

\begin{tabular}{ccccc}
\hline & N/C-900 & Fe-N/C-0.025-900 & Fe-N/C-0.05-900 & Fe-N/C-0.075-900 \\
\hline Total pore volume $\left(\mathrm{cm}^{3} \mathrm{~g}^{-1}\right)$ & 1.019 & 1.242 & 1.105 & 1.035 \\
Specific surface area $\left(\mathrm{m}^{2} \mathrm{~g}^{-1}\right)$ & 983.2 & 754.6 & 812.1 & 725.5 \\
\hline
\end{tabular}

The microscopic structure of the Fe-ZIF-0.05 precursor and the Fe-N/C-0.05-900 sample was investigated by using TEM and HRTEM. As exhibited in Figure $4 \mathrm{a}-\mathrm{c}$, the precursor showed a typical dodecahedral structure with a smooth surface. The particle size was approximately $200 \mathrm{~nm}$, which is consistent with the result of the SEM results. After being carbonized at $900{ }^{\circ} \mathrm{C}$, the dodecahedron structure shrank, with the surface becoming rougher than before (Figure $4 \mathrm{~d}-\mathrm{f}$ ). Interestingly, no metal particles or aggregates were detected in the product, which proves that the Fe species should be uniformly dispersed in the whole carbon framework at the atomic level, thereby providing a large number of active sites for the electrocatalytic reaction. Notably, a large number of porous structures were detected on the surface of the sample, which are thought to have resulted from the volatilization of $\mathrm{Zn}$ atoms during the carbonization process.

To further observe the microstructures, the high-resolution TEM (HRTEM) was performed. Figure $4 \mathrm{f}$ exhibits the visible fringes with an interplanar spacing of $0.34 \mathrm{~nm}$, which corresponds to the (002) crystal plane of graphite carbon, further proving the formation of graphitization after the carbonization at high temperature. The formation of graphitic carbon is contributed from the catalytic effect of Fe species. This result is also consistent with those of the Raman spectra. Due to the limitations of our experimental conditions, we could not carry out spherical aberration-corrected transmission electron microscope (SACTEM) or the X-ray adsorption fine structure (XAFS) to directly identify the atomic Fe sites embedded into carbon. However, we have attempted to improve the molar ratio of $\mathrm{Fe}^{3+} / \mathrm{Zn}^{2+}$ to 0.15 in order to investigate the composition, structure, and morphology of products with increased iron content. The XRD pattern in Figure S2a indicates that Fe-ZIF0.15 precursor still inherited the original structure from pure ZIF-8, which is consistent with the other proportional precursor. However, the obvious XDR diffraction peaks for 
graphitized carbon at $2 \theta$ of $26.2^{\circ}$ and the identifiable lattice fringe with $d=0.34 \mathrm{~nm}$ were both detected. These results can be attributed to the Fe specified, which are beneficial to the formation of graphitic carbon at a high temperature. More interestingly, the characteristic diffraction peak for iron at $2 \theta=45.9^{\circ}$ was simultaneously observed, which had a good fit with the equally distributed iron nanoparticles in Figure S2c,d. This result demonstrates that increasing the iron content will result in the aggregation of atomic iron. In turn, in the case of a very low content of iron, it is super-distributed in the skeleton at the atomic level. Figure $4 \mathrm{~g}-\mathrm{k}$ shows the dark-field scanning transmission electron microscopy (STEM) and EDX elemental mapping of Fe-N/C-0.05-900. All the atoms comprising Fe, N, C, and $\mathrm{O}$ were evenly distributed in the carbon nano skeleton. More importantly, it provides evidence to confirm the existence of iron atoms. The sum spectrum of the maps is also displayed in Figure S3.

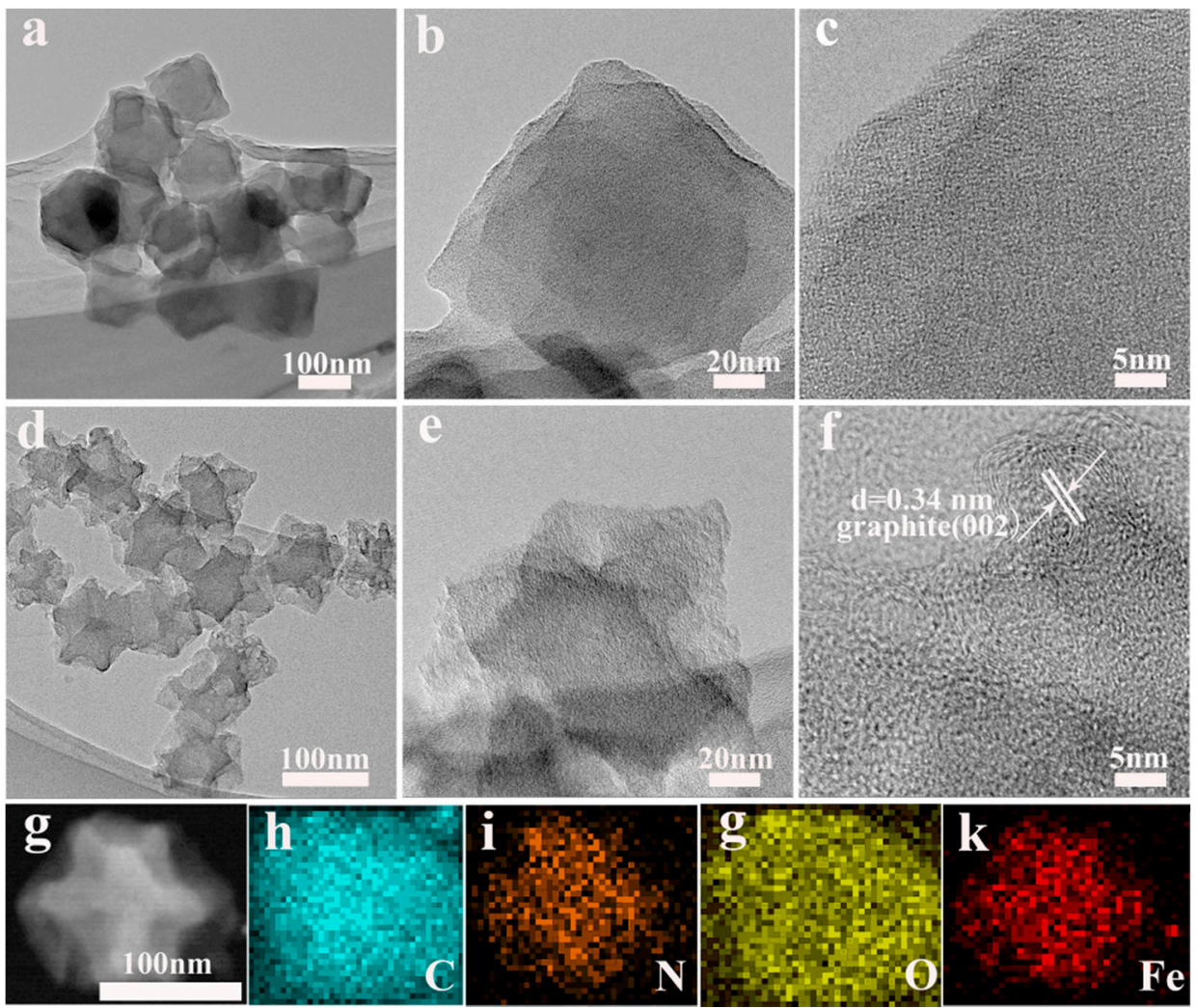

Figure 4. TEM images of the precursors Fe-ZIF-0.05 (a-c), Fe-N/C-0.05-900 (d-f), HAADF-STEM images and elemental mapping of Fe-N/C-0.05-900 (g-k).

X-ray photoelectron spectroscopy (XPS) was applied to probe the surface elemental and bonding configurations of Fe-N/C-0.05-900. Figure S4 shows the full spectrum of the Fe-N/C-0.05-900 sample. Although the intensity of the carbon signal was very high, a fine scan for Fe was still detectable. The element atomic contents of Fe, C, N, and O in Fe-N/C-0.05-900 were measured to be 1.20, 87.76, 7.34 and 3.70 at\%. (Table S1). As for the $\mathrm{C}$ 1s (Figure 5a), the peaks at $284.6 \mathrm{eV}, 285.8 \mathrm{eV}, 287.8 \mathrm{eV}, 289.9 \mathrm{eV}$ and $292.0 \mathrm{eV}$ were due to the $\mathrm{C}-\mathrm{C} / \mathrm{C}-\mathrm{H}, \mathrm{C}-\mathrm{N} / \mathrm{C}-\mathrm{O}, \mathrm{O}=\mathrm{C}-\mathrm{O}$, carbonate, and $\pi-\pi^{*}$ bonds, respectively. These results confirm the formation of N-doped carbon [41] and graphitized carbon [42]. Focusing on the high-resolution XPS spectrum of N 1s (Figure 5b), the peaks at $398.2 \mathrm{eV}, 399.8 \mathrm{eV}, 400.8 \mathrm{eV}$ and $402.7 \mathrm{eV}$ can be attributed to the coordination environments of pyridinic-N [43], pyrrolic-N [44], graphitic-N [45], and oxidized-N [46]. These findings indicate that $\mathrm{N}$ elements have been successfully incorporated into the carbon matrix, in which pyridinic $\mathrm{N}$ as reported would act as the active component to modify the electronic structure of carbon and coordinate with the metal forming the highly active Fe-Nx moieties [20,47], while 
graphitic $\mathrm{N}$ could show a synergistic effect in helping $\mathrm{O}-\mathrm{O}$ bond splitting [19]. Accordingly, the XPS peak of N 1s at bonding energy of $399.0 \mathrm{eV}$ was identified to be $\mathrm{Fe}-\mathrm{Nx}$, which acts as the active sites for the ORR [48]. Furthermore, the presence of $\mathrm{Fe}$ in the $\mathrm{Fe}-\mathrm{N} / \mathrm{C}-0.05-$ 900 can also be validated by the evidence that several Fe peaks including Fe (II) $2 \mathrm{p} 3 / 2$ (710.4 eV), Fe (III) 2p3/2 (714.3 eV), Fe (II) 2p1/2 (723.4 eV), and Fe (III) 2p1/2 (725.6 eV) can be observed in Figure 5e. In addition, the satellite peak was observed at $719.2 \mathrm{eV}$.
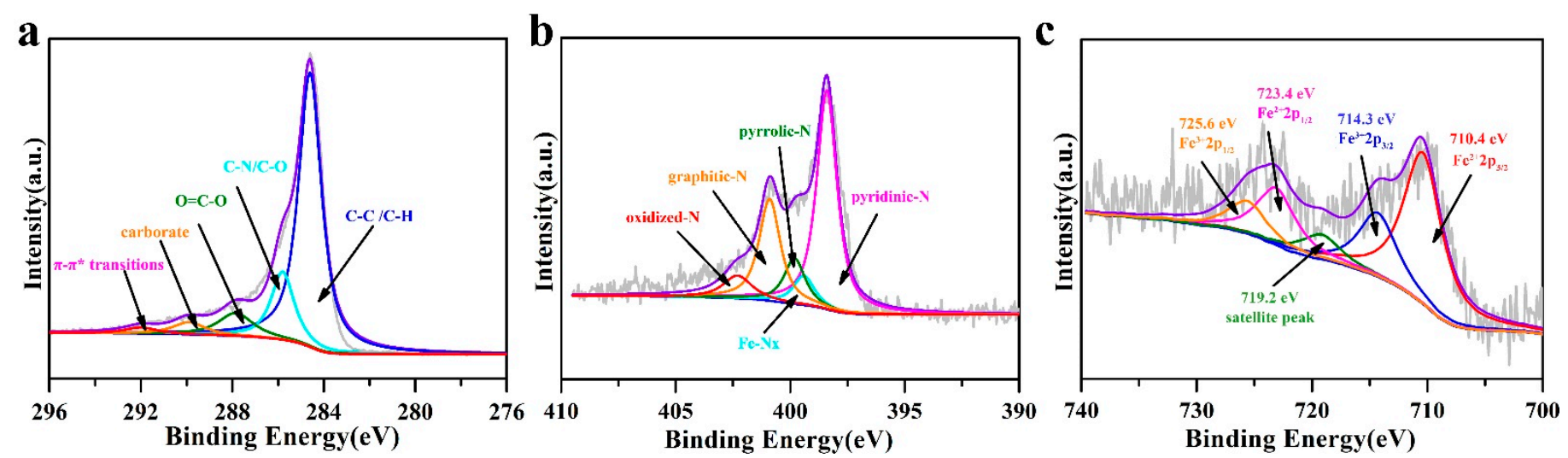

Figure 5. XPS spectra of Fe-N/C-0.05-900: (a) C 1s, (b) N 1s, and (c) Fe 2p.

\subsection{ORR Catalytic Results}

The electrocatalytic activity of the Fe-N/C samples with different $\mathrm{Fe}^{3+} / \mathrm{Zn}^{2+}$ molar ratios were evaluated in a three-electrode system. As shown in Figure 6a, the ORR polarization curves were recorded in oxygen saturated $0.1 \mathrm{M} \mathrm{KOH}$, and invested the influence of Fe content on electrocatalytic performance. Obviously, all the catalysts embedded with a small amount of Fe were more active in terms of ORR activity than the pure ZIF-8 (N/C) in alkaline medium. Among all the Fe-containing samples, the Fe-N/C-0.05-900 sample displayed the best catalytic activity with a high onset potential $\left(E_{\text {onset }}=0.99 \mathrm{~V}\right)$, which is comparable to a commercial $20 \% \mathrm{Pt} / \mathrm{C}\left(\mathrm{E}_{\text {onset }}=0.10 \mathrm{~V}\right)$ and many reported Fe-N/Cbased catalysts (Table S2). Furthermore, the half-wave potential of the Fe-N/C-0.05-900 sample $\left(E_{1 / 2}=0.885 \mathrm{~V}\right)$ shifted forward by approximately $24 \mathrm{mV}$ than $20 \% \mathrm{Pt} / \mathrm{C}$ catalyst $\left(\mathrm{E}_{1 / 2}=0.861 \mathrm{~V}\right)$, indicating that the $\mathrm{Fe}-\mathrm{N} / \mathrm{C}-0.05-900$ catalyst had similar ORR reaction kinetics to standard $\mathrm{Pt} / \mathrm{C}$ catalysts, and is more prominent in the region of kinetics and diffusion mixing control.

The electron transfer kinetics of $\mathrm{Fe}-\mathrm{N} / \mathrm{C}-0.05-900$ was further investigated by LSV curves at different rotation speeds (400-1600 rpm). As displayed in Figure $6 \mathrm{~b}$, the current densities of Fe-N/C-0.05-900 increased with the increase in rotation speed, suggesting the shortened diffusion distance of oxygen at high rotating speeds. The inset in Figure $6 \mathrm{~b}$ illustrates the good linearity of $\mathrm{K}-\mathrm{L}$ plots for $\mathrm{Fe}-\mathrm{N} / \mathrm{C}-0.05-900$, reflecting the first order reaction kinetics related to the $\mathrm{O}_{2}$ concentration. In addition, based on the $\mathrm{K}-\mathrm{L}$ equation, the electron transfer numbers (n) of Fe-N/C $-0.05-900(n=3.91)$ and $20 \% \mathrm{Pt} / \mathrm{C}$ $(n=3.95)$ were determined to be close to 4 , indicating that the catalyst follows a dominant four-electron pathway when performing ORR electrocatalysis (Figure 6c). The $\mathrm{H}_{2} \mathrm{O}_{2}$ yield of all the Fe-N/C catalysts was less than 5\%, revealing that these materials toward ORR catalysis are mainly based on the $4 \mathrm{e}^{-}$reaction pathway. Figure S5 shows the Tafel plots derived from the kinetic-controlled region in the ORR polarization curves. Compared with the well-established $20 \% \mathrm{Pt} / \mathrm{C}$, the Fe-N/C-0.05-900 catalyst exhibited an approximate Tafel slope, further indicating their similar ORR mechanisms and kinetic characteristics to $20 \% \mathrm{Pt} / \mathrm{C}$ [37]. 


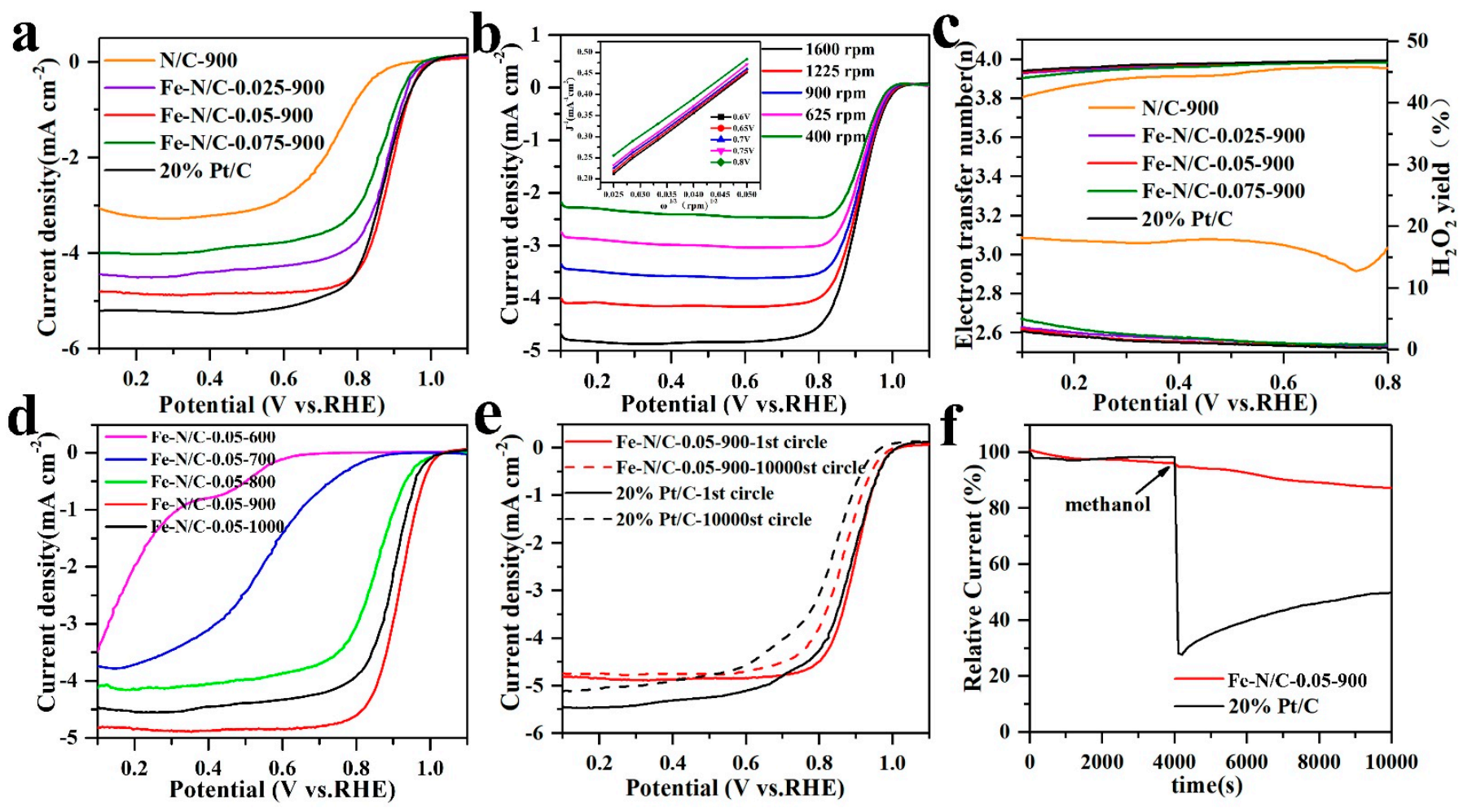

Figure 6. (a) LSV curves of Fe-N/C with different molar ratios of iron and 20\% Pt/C in $\mathrm{O}_{2}-$ saturated $0.1 \mathrm{M} \mathrm{KOH}$, (b) LSV curves of $\mathrm{Fe}-\mathrm{N} / \mathrm{C}-0.05-900$ obtained at different rotation rates and $\mathrm{K}-\mathrm{L}$ plots, (c) transferred electron numbers and $\mathrm{H}_{2} \mathrm{O}_{2}$ yield at different potentials, (d) ORR curves of the samples at different temperatures in $0.1 \mathrm{M} \mathrm{KOH}$, (e) Stability tests of Fe-N/C-0.05-900 and 20\% Pt/C catalysts: the LSV curves before and after 10,000 times CV. (f) Chronoamperometric responses of $\mathrm{Fe}-\mathrm{N} / \mathrm{C}-0.05-900$ and $20 \% \mathrm{Pt} / \mathrm{C}$, in which $3 \mathrm{M}$ methanol was added at $4000 \mathrm{~s}$.

The various versions of $\mathrm{Fe}-\mathrm{N} / \mathrm{C}-0.05$ catalysts obtained by carbonizing the Fe-ZIF0.05 precursor at $600,700,800,900$ and $1000^{\circ} \mathrm{C}$ were extensively investigated, respectively. The LSV voltammograms in $\mathrm{O}_{2}$-saturated $0.1 \mathrm{M} \mathrm{KOH}$ solution at a rotating speed of $1600 \mathrm{rpm}$ are compared in Figure 6d. It was found that the measurable steady-state ORR current could be detected for both the Fe-N/C-0.05-600 and Fe-N/C-0.05-700 samples, although the onset potential and half-wave potential were very low. When the temperature was further increased to $800^{\circ} \mathrm{C}$, the ORR activity exhibited a significant improvement. To understand this appearance, the overall $\mathrm{N} 1 \mathrm{~s}$ and $\mathrm{C} 1 \mathrm{~s}$ determined by XPS are summarized in Figure S6. The N elemental quantification analysis (Table S3) indicates that increasing the heating temperature led to a decline in the total $\mathrm{N}$ content. Nevertheless, the continuous decrease in the $\mathrm{N}$ content did not lead to a decline in activity. This result is coincident with the reported reference [20], demonstrating that the $\mathrm{N}$ content in the catalysts might be sufficient. It is worth noting that a new bond of Fe-Nx at $399.0 \mathrm{eV}$ formed at $800{ }^{\circ} \mathrm{C}$ (Figure S6a), which suggests that $800{ }^{\circ} \mathrm{C}$ is the crucial point for generating active sites toward ORR. The maximum activity was reached at $900{ }^{\circ} \mathrm{C}$. This can be attributed to (i) the formation of a larger number of active sites; (ii) graphitization increasing with temperature by the gradual narrowing of $\mathrm{C}-\mathrm{C}$ peaks in (Figure S6b); and (iii) the medium particle size $(105 \mathrm{~nm})$, proper total pore volume $\left(1.105 \mathrm{~cm}^{3} \mathrm{~g}^{-1}\right)$, and high surface area $\left(812.1 \mathrm{~m}^{2} \mathrm{~g}^{-1}\right)$. All these reasons affect the ORR catalytic performance. When the temperature was further increased up to $1000{ }^{\circ} \mathrm{C}$, it was found that although the $E_{\text {onset }}$ and $E_{\text {half-wave }}$ did not change significantly, the $J_{\text {limit }}$ decreased obviously. We attribute this result to the collapse of the product structure at a high temperature, which will affect the diffusion of the electrolyte in the electrode material, resulting in the decay of activity.

The stability of the catalyst is an important indicator to evaluate the ORR performance. Figure 6e shows the ORR polarization curves of $\mathrm{Fe}-\mathrm{N} / \mathrm{C}-0.05-900$ and $20 \% \mathrm{Pt} / \mathrm{C}$ after $10,000 \mathrm{CV}$ tests in $\mathrm{O}_{2}$-saturated $0.1 \mathrm{M} \mathrm{KOH}$. The half-wave potential of $\mathrm{Fe}-\mathrm{N} / \mathrm{C}-0.05$ 
900 only shifted negatively by $32 \mathrm{mV}$, while the commercial $20 \% \mathrm{Pt} / \mathrm{C}$ catalyst shifted negatively by $57 \mathrm{mV}$, indicating the much better stability of Fe-N/C-0.05-900 compared with commercial 20\% Pt/C. Furthermore, the stability of Fe-N/C-0.05-900 and 20\% Pt/C was further evaluated by chronoamperometry $(\mathrm{I} / \mathrm{T})$ at a constant potential of $0.885 \mathrm{~V}$ in an oxygen saturated 0.1 M KOH electrolyte. As shown in Figure S7, the Fe-N/C-0.05-900 electrocatalyst maintained $90.1 \%$ of the initial current density after $10,000 \mathrm{~s}$, while the current value for $20 \% \mathrm{Pt} / \mathrm{C}$ decreased by $14.6 \%$, indicating the more superior durability of Fe-N/C-0.05-900 to the commercial 20\% Pt/C catalyst. Such remarkable stability is thought to be due to the unique porous graphitic carbon structure derived from the ZIF-8 framework, which would act as an anchor to stabilize Fe specified in the composite and prevent $\mathrm{Fe}-\mathrm{N}$ active sites from aggregation and migration in the process of electrocatalysis. Finally, with the addition of $3 \mathrm{M}$ methanol, significant methanol oxidation current response was observed for Pt/C, while this was not observed for Fe-N/C-0.05-900, demonstrating its excellent resistance to methanol poisoning (Figure 6f).

\section{Conclusions}

In summary, a series of Fe-N/C catalysts composed of super-dispersed Fe-N active sites embedded into porous graphitic carbon without metallic agglomeration were synthesized via the chemical doping of Fe ions into ZIF-8 frameworks and suffered from one-step thermal treatment in $\mathrm{N}_{2}$ gas. The Fe-N/C catalyst inherited the porous structure of ZIF-8 including some microporous and abundant mesoporous that generated more effective porosity for mass transfer in ORR. During the conversion, the particle size and composition of catalysts can be controlled by adjusting the $\mathrm{Fe}^{3+} / \mathrm{Zn}^{2+}$ molar ratio and heating temperature, which allowed us to study the size-dependent ORR activity of Pt-free catalysts. More importantly, there was no agglomeration when the content of Fe was very low. The Fe-N specified were highly-dispersed into the porous carbon phases, which exposed a large number of active sites and finally drove the more excellent ORR activity, stability, and poison tolerance, even being superior to a commercial Pt catalyst.

Supplementary Materials: The following are available online at https:/ / www.mdpi.com/article/10 .3390/nano11082106/s1, Figure S1: (a) SEM image of Fe-ZIF-0.05 precursor and (b-f) SEM images of $\mathrm{Fe}-\mathrm{N} / \mathrm{C}-0.05-600, \mathrm{Fe}-\mathrm{N} / \mathrm{C}-0.05-700, \mathrm{Fe}-\mathrm{N} / \mathrm{C}-0.05-800, \mathrm{Fe}-\mathrm{N} / \mathrm{C}-0.05-900$ and Fe-N/C-0.05-1000. The illustration shows the particle size distribution, Figure S2: (a) XRD and (b-d) TEM images of Fe-N/C-0.15-900, Figure S3: The sum spectrum of the maps for Fe-N/C-0.05-900, Figure S4: The full spectrum of Fe-N/C-0.05-900, Table S1: The element atomic contents of Fe, C, N and O in Fe-N/C-0.05-900 by XPS measurement, Table S2: The comparison of ORR activity between our work and the references, Figure S5: Tafel curves of Fe-N/C-0.05-900 and 20\% Pt/C catalysts, Figure S6: The evolution of XPS N 1s (a) and C 1s (b) spectra of the Fe-N/C catalysts with increasing heating temperature up to $1000{ }^{\circ} \mathrm{C}$, Table S3:The $\mathrm{N}$ elemental quantification determined by XPS analysis, Figure S7: Chronoamperometric curves of Fe-N/C-0.05-900 and 20\% Pt/C electrodes in $\mathrm{O}_{2}$-saturated $0.1 \mathrm{M} \mathrm{KOH}$ at a rotating speed of $1600 \mathrm{rpm}$, the potential was controlled at $0.75 \mathrm{~V}$ for $10000 \mathrm{~s}$.

Author Contributions: Synthesis, characterization and original draft preparation, X.Y.W. and R.H.W.; investigation, resources and data curation, Z.W.L. and Y.Q.J.; review, editing and project administration, J.C.L. All authors have read and agreed to the published version of the manuscript.

Funding: This research received no external funding.

Institutional Review Board Statement: Not applicable.

Informed Consent Statement: Not applicable.

Acknowledgments: This work was supported by the Natural Science Foundation of China (21801069, 21601055); Natural Science Foundation of Heilongjiang Province (LH2019B013); Scientific Research Funds of University Affiliated to Heilongjiang Province (KJCX201913); the University Program for Young Scholars with Creative Talents in Heilongjiang Province (UNPYSCT-2018013,UNPYSCT2017118); thee China Postdoctoral Science Foundation (2017M611406); the Heilongjiang Provincial 
Postdoctoral Science Foundation LBH-Z18232); and the Heilongjiang University Excellent Youth Foundation.

Conflicts of Interest: There is no conflict of interest.

\section{References}

1. Li, W.; Wang, D.D.; Zhang, Y.Q.; Tao, L.; Wang, T.H.; Zou, Y.Q.; Wang, Y.Y.; Chen, R.; Wang, S.Y. Defect Engineering for Fuel-Cell Electrocatalysts. Adv. Mater. 2020, 32, 1907879. [CrossRef]

2. Yu, P.; Wang, L.; Sun, F.F.; Xie, Y.; Liu, X.; Ma, J.Y.; Wang, X.W.; Tian, C.G.; Li, J.H.; Fu, H.G. Co Nanoislands Rooted on Co-N-C Nanosheets as Efficient Oxygen Electrocatalyst for Zn-Air Batteries. Adv. Mater. 2019, 31, 1901666. [CrossRef]

3. Xu, N.N.; Zhang, Y.X.; Zhang, T.; Liu, Y.Y.; Qiao, J.L. Efficient quantum dots anchored nanocomposite for highly active ORR/OER electrocatalyst of advanced metal-air batteries. Nano Energy 2019, 57, 176-185. [CrossRef]

4. Hu, X.; Min, Y.; Ma, L.L.; Lu, J.H.; Li, H.C.; Liu, W.J.; Chen, J.J.; Yu, H.Q. Iron-nitrogen doped carbon with exclusive presence of FexN active sites as an efficient ORR electrocatalyst for Zn-air battery. Appl. Catal. B 2020, 268, 118405. [CrossRef]

5. Liu, X.; Wang, L.; Yu, P.; Tian, C.G.; Sun, F.F.; Ma, J.Y.; Li, W.; Fu, H.G. A Stable Bifunctional Catalyst for Rechargeable Zinc-Air Batteries: Iron-Cobalt Nanoparticles Embedded in a Nitrogen-Doped 3D Carbon Matrix. Angew. Chem. Int. Ed. 2018, 57, 16166-16170. [CrossRef]

6. Pargoletti, E.; Salvi, A.; Giordana, A.; Cerrato, G.; Cerrato, M.; Minguzzi, A.; Cappelletti, G.; Vertova, A. ORR in Non-Aqueous

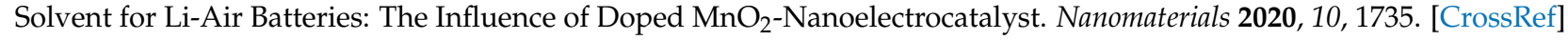

7. Suryaa, K.; Michaela, M.S.; Prabaharanb, S.R.S. A review on advancement in non-noble metal based oxides as bifunctional catalysts for rechargeable non-aqueous Li/air battery. Solid State Ion. 2018, 317, 89-96. [CrossRef]

8. Wan, X.; Liu, X.F.; Li, Y.C.; Yu, R.G.; Zheng, L.; Yan, W.H.; Wang, H.; Xu, M.; Shui, J.L. Fe-N-C electrocatalyst with dense active sites and efficient mass transport for high-performance proton exchange membrane fuel cells. Nat. Catal. 2019, 2, 259-268. [CrossRef]

9. Fu, X.G.; Li, N.; Ren, B.H.; Jiang, G.P.; Liu, Y.R.; Hassan, F.M.; Su, D.; Zhu, J.B.; Yang, L.; Bai, Z.Y.; et al. Tailoring FeN 4 Sites with Edge Enrichment for Boosted Oxygen Reduction Performance in Proton Exchange Membrane Fuel Cell. Adv. Energy Mater. 2019, 9, 1803737. [CrossRef]

10. Zhu, C.Z.; Shi, Q.R.; Xu, B.Z.; Fu, S.F.; Wang, G.; Yang, C.; Yao, S.Y.; Song, J.H.; Zhou, H.; Du, D.; et al. Hierarchically Porous $\mathrm{M}-\mathrm{N}-\mathrm{C}(\mathrm{M}=\mathrm{Co}$ and $\mathrm{Fe})$ Single-Atom Electrocatalysts with Robust MNx Active Moieties Enable Enhanced ORR Performance. Adv. Energy Mater. 2018, 8, 1801956. [CrossRef]

11. Tian, P.F.; Wang, Y.H.; Li, W.; Song, S.W.; Zhou, S.Y.; Gao, H.W.; Xu, H.Q.; Tian, X.Q.; Zang, J.B. A salt induced gelatin crosslinking strategy to prepare Fe-N doped aligned porous carbon for efficient oxygen reduction reaction catalysts and high-performance supercapacitors. J. Catal. 2020, 382, 109-120. [CrossRef]

12. Zhang, H.G.; Chung, H.T.; Cullen, D.A.; Wagner, S.; Kramm, U.I.; More, K.L.; Zelenay, P.; Wu, G. High-performance fuel cell cathodes exclusively containing atomically dispersed iron active sites. Energy Environ. Sci. 2019, 12, 2548-2558. [CrossRef]

13. Xia, D.S.; Yang, X.; Xie, L.; Wei, Y.P.; Jiang, W.L.; Dou, M.; Li, X.I.; Li, J.; Gan, L.; Kang, F.Y. Direct Growth of Carbon Nanotubes Doped with Single Atomic Fe- $\mathrm{N}_{4}$ Active Sites and Neighboring Graphitic Nitrogen for Efficient and Stable Oxygen Reduction Electrocatalysis. Adv. Funct. Mater. 2019, 29, 1906174. [CrossRef]

14. Qu, X.I.; Han, Y.; Chen, Y.H.; Lin, J.X.; Li, G.; Yang, J.; Jiang, Y.X.; Sun, S.G. Stepwise pyrolysis treatment as an efficient strategy to enhance the stability performance of $\mathrm{Fe}-\mathrm{N}_{X} / \mathrm{C}$ electrocatalyst towards oxygen reduction reaction and proton exchange membrane fuel cell. Appl. Catal. B 2021, 295, 120311. [CrossRef]

15. Kumar, K.; Dubau, L.; Mermoux, M.; Li, J.K.; Zitolo, A.; Nelayah, J.; Jaouen, F.; Maillard, F. On the Influence of Oxygen on the Degradation of Fe-N-C Catalysts. Angew. Chem. Int. Ed. 2020, 59, 3235-3243. [CrossRef]

16. Jiang, L.I.; Duan, J.J.; Zhu, J.W.; Chen, S.; Antonietti, M. Iron-Cluster-Directed Synthesis of 2D/2D Fe-N-C/MXene Superlatticelike Heterostructure with Enhanced Oxygen Reduction Electrocatalysis. ACS Nano 2020, 14, 2436-2444. [CrossRef]

17. Li, J.K.; Jiao, L.; Wegener, E.; Richard, L.L.; Liu, E.; Zitolo, A.; Sougrati, M.T.; Mukerjee, S.; Zhao, Z.P.; Huang, Y. Evolution Pathway from Iron Compounds to $\mathrm{Fe}_{1}(\mathrm{II})-\mathrm{N}_{4}$ Sites through Gas-Phase Iron during Pyrolysis. J. Am. Chem. Soc. 2020, 142, 1417-1423. [CrossRef] [PubMed]

18. Zhang, H.G.; Osgood, H.; Xie, X.H.; Shao, Y.Y.; Wu, G. Engineering nanostructures of PGM-free oxygen-reduction catalysts using metal-organic frameworks. Nano Energy 2017, 31, 331-350. [CrossRef]

19. Jiang, W.J.; Gu, L.; Li, L.; Zhang, Y.; Zhang, L.J.; Wang, J.Q.; Hu, J.S.; Wei, Z.D.; Wan, L.J. Understanding the High Activity of $\mathrm{Fe}-\mathrm{N}-\mathrm{C}$ Electrocatalysts in Oxygen Reduction: $\mathrm{Fe} / \mathrm{Fe}_{3} \mathrm{C}$ Nanoparticles Boost the Activity of $\mathrm{Fe}-\mathrm{N}_{\mathrm{x}}$. J. Am. Chem. Soc. 2016, 138, 3570-3578. [CrossRef]

20. Zhang, H.G.; Hwang, S.; Wang, M.Y.; Feng, Z.X.; Karakalos, S.; Luo, L.I.; Qiao, Z.; Xie, X.H.; Wang, C.M.; Su, D.; et al. Single Atomic Iron Catalysts for Oxygen Reduction in Acidic Media: Particle Size Control and Thermal Activation. J. Am. Chem. Soc. 2017, 139, 14143-14149. [CrossRef] [PubMed]

21. Choi, C.H.; Park, S.H.; Woo, S.I. Facile growth of N-doped CNTs on Vulcan carbon and the effects of iron content on electrochemical activity for oxygen reduction reaction. Int. J. Hydrogen Energy 2012, 37, 4563-4570. [CrossRef]

22. Wang, Y.; Pan, Y.; Zhu, L.K.; Yu, H.H.; Duan, B.Y.; Wang, R.W. Solvent-free assembly of Co/Fe-containing MOFs derived N-doped mesoporous carbon nanosheets for ORR and HER. Carbon 2019, 146, 671-679. [CrossRef] 
23. Ren, Q.; Wang, H.; Lu, X.F.; Tong, Y.X.; Li, G.R. Recent Progress on MOF-Derived Heteroatom-Doped Carbon-Based Electrocatalysts for Oxygen Reduction Reaction. Adv. Sci. 2018, 5, 1700515. [CrossRef]

24. Song, G.Q.; Wang, Z.Q.; Wang, L.; Li, G.R.; Huang, M.J.; Yin, F.X. Preparation of MOF(Fe) and its catalytic activity for oxygen reduction reaction in an alkaline electrolyte. Chin. J. Catal. 2014, 35, 185-195. [CrossRef]

25. Deng, Y.J.; Chi, B.; Tian, X.L.; Cui, Z.M.; Liu, E.; Jia, Q.Y.; Fan, W.J.; Wang, G.H.; Dang, D.; Li, M.; et al. g-C $3 \mathrm{~N}_{4}$ promoted MOF derived hollow carbon nanopolyhedra doped with high density/fraction of single Fe atoms as an ultra-high performance non precious catalyst towards acidic ORR and PEM fuel cells. J. Mater. Chem. A 2019, 7, 5020-5030. [CrossRef]

26. Ye, L.; Chai, G.L.; Wen, Z.H. Zn-MOF-74 Derived N-Doped Mesoporous Carbon as pH-Universal Electrocatalyst for Oxygen Reduction Reaction. Adv. Funct. Mater. 2017, 27, 1606190. [CrossRef]

27. Li, F.L.; Shao, Q.; Huang, X.Q.; Lang, J.P. Nanoscale Trimetallic Metal-Organic Frameworks Enable Efficient Oxygen Evolution Electrocatalysis. Angew. Chem. Int. Ed. 2018, 57, 1888-1892. [CrossRef]

28. Tran, T.N.; Shin, C.H.; Lee, B.J.; Samdani, J.; Park, J.D.; Kang, T.H.; Yu, J.S. Fe-N-functionalized carbon electrocatalyst derived from a zeolitic imidazolate framework for oxygen reduction: Fe and $\mathrm{NH}_{3}$ treatment effects. Catal. Sci. Technol. 2018, 8, 5368-5381. [CrossRef]

29. Ye, G.Y.; He, Q.; Liu, S.Q.; Zhao, K.M.; Su, Y.K.; Zhu, W.W.; Huang, R.J.; He, Z. Cage-confinement of gas-phase ferrocene in zeolitic imidazolate frameworks to synthesize high loading and atomically dispersed $\mathrm{Fe}-\mathrm{N}$ codoped carbon for efficient oxygen reduction reaction. J. Mater. Chem. A 2019, 7, 16508-16515. [CrossRef]

30. Liu, J.; Fan, C.H.; Liu, G.B.; Jiang, L.H. MOF-derived dual metal (Fe, Ni)-nitrogen-doped carbon for synergistically enhanced oxygen reduction reaction. Appl.Surf. Sci. 2021, 538, 148017. [CrossRef]

31. Huang, J.W.; Cheng, Q.Q.; Huang, Y.C.; Yao, H.C.; Zhu, H.B.; Yang, H. Highly Efficient Fe-N-C Electrocatalyst for Oxygen Reduction Derived from Core-Shell-Structured Fe(OH) $)_{3} @$ Zeolitic Imidazolate Framework. ACS Appl. Energy Mater. 2019, 2 , 3194-3203. [CrossRef]

32. Guo, Z.Y.; Liu, S.M.; Hu, X.; Song, J.; Xu, K.; Ye, Q.; Xu, G.Z.; Deng, Z.F. Core-shell structured metal organic framework materials derived cobalt/iron-nitrogen Co-doped carbon electrocatalysts for efficient oxygen Reduction. Int. J. Hydrogen Energy 2021, 46, 9341-9350. [CrossRef]

33. Yang, X.B.; Wen, Z.D.; Wu, Z.L.; Luo, X.T. Synthesis of ZnO/ZIF-8 hybrid photocatalysts derived from ZIF-8 with enhanced photocatalytic Activity. Inorg. Chem. Front. 2018, 5, 687-693. [CrossRef]

34. Jing, Y.Q.; Wang, J.N.; Yu, B.H.; Lun, J.; Cheng, Y.Y.; Xiong, B.; Lei, Q.; Yang, Y.F.; Cheng, L.Y.; Zhao, M.Q. A MOF-derived ZIF-8@Zn $\mathrm{n}_{1-\mathrm{x}} \mathrm{Ni}_{\mathrm{x}} \mathrm{O}$ photocatalyst with enhanced photocatalytic activity. RSC Adv. 2017, 7, 42030-42035. [CrossRef]

35. Su, F.B.; Poh, C.K.; Chen, J.S.; Xu, G.W.; Wang, D.; Li, Q.; Lin, J.Y.; Lou, X.W. Nitrogen-containing microporous carbon nanospheres with improved capacitive properties. Energy Environ. Sci. 2011, 4, 717-724. [CrossRef]

36. Xuan, C.J.; Hou, B.S.; Xia, W.W.; Peng, Z.K.; Shen, T.; Xin, H.L.; Zhang, G.A.; Wang, D.L. From a ZIF-8 polyhedron to threedimensional nitrogen doped hierarchical porous carbon: An efficient electrocatalyst for the oxygen reduction reaction. J. Mater. Chem. A 2018, 6, 10731-10739. [CrossRef]

37. Li, S.J.; Wang, R.H.; Yang, X.; Wu, J.; Meng, H.Y.; Xu, H.L.; Ren, Z.Y. Binary Metal Phosphides with MoP and FeP Embedded in P, N Doped Graphitic Carbon As Electrocatalysts for Oxygen Reduction. ACS Sustain. Chem. Eng. 2019, 7, 11872-11884. [CrossRef]

38. Sun, K.J.; Fan, F.T.; Xia, H.A.; Feng, Z.C.; Li, W.X.; Li, C. Framework Fe Ions in Fe-ZSM-5 Zeolite Studied by UV Resonance Raman Spectroscopy and Density Functional Theory Calculations. J. Phys. Chem. C 2008, 112, 16036-16041. [CrossRef]

39. Ferrari, A.C.; Meyer, J.C.; Scardaci, V.; Casiraghi, C.; Lazzeri, M.; Mauri, F.; Piscanec, S.; Jiang, D.; Novoselov, K.S.; Roth, S.; et al. Raman Spectrum of Graphene and Graphene Layers. Phys. Rev. Lett. 2006, 97, 187401. [CrossRef]

40. Zhang, L.J.; Su, Z.X.; Jiang, F.L.; Yang, L.I.; Qian, J.J.; Zhou, Y.F.; Lia, W.M.; Hong, M.C. Highly graphitized nitrogen-doped porous carbon nanopolyhedra derived from ZIF-8 nanocrystals as efficient electrocatalysts for oxygen reduction reactions. Nanoscale 2014, 6, 6590-6602. [CrossRef] [PubMed]

41. Guo, Y.C.; Feng, L.; Wang, X.M.; Zhang, X. Confined pyrolysis transformation of ZIF-8 to hierarchically ordered porous Zn-N-C nanoreactor for efficient $\mathrm{CO}_{2}$ photoconversion under mild Conditions. J. Catal. 2020, 390, 213-223. [CrossRef]

42. Chen, H.; You, S.J.; Ma, Y.Y.; Zhang, C.Y.; Jing, B.J.; Cai, Z.; Tang, B.; Ren, N.Q.; Zou, J.L. Carbon Thin-Layer-Protected Active Sites for ZIF-8-Derived Nitrogen-Enriched Carbon Frameworks/Expanded Graphite as Metal-Free Catalysts for Oxygen Reduction in Acidic Media. Chem. Mater. 2018, 30, 6014-6025. [CrossRef]

43. Liu, J.; Song, P.; Xu, W.L. Structure-activity relationship of doped-nitrogen (N)-based metal free active sites on carbon for oxygen reduction reaction. Carbon 2017, 115, 763-772. [CrossRef]

44. Xue, S.; Yu, Y.J.; Wei, S.S.; Xu, B.B.; Lei, J.; Ban, R.C.; Wu, Q.H.; Zheng, M.S.; Li, J. Nitrogen-doped porous carbon derived from ZIF-8 as a support of electrocatalyst for enhanced oxygen reduction reaction in acidic Solution. J. Taiwan Inst. Chem. E 2018, 91, 539-547. [CrossRef]

45. Cao, P.K.; Liu, Y.M.; Quan, X.; Zhao, J.J.; Chen, S.; Yu, H.T. Nitrogen-doped hierarchically porous carbon nanopolyhedras derived from core-shell ZIF-8@ZIF-8 single crystals for enhanced oxygen reduction Reaction. Catal. Today 2019, 327, 366-373. [CrossRef]

46. Lai, L.F.; Potts, J.R.; Zhan, D.; Wang, L.; Poh, C.K.; Tang, C.H.; Gong, H.; Shen, Z.X.; Lin, J.Y.; Ruoff, R.S. Exploration of the active center structure of nitrogen-doped graphene-based catalysts for oxygen reduction reaction. Energy Environ. Sci. 2012, 5, 7936-7942. [CrossRef] 
47. Zheng, X.J.; Wu, J.; Cao, X.C.; Abbott, J.; Jin, C.; Wang, H.B.; Strasser, P.; Yang, R.Z.; Chen, X.; Wu, G. N-, P-, and S-doped graphene-like carbon catalysts derived from onium salts with enhanced oxygen chemisorption for Zn-air battery cathodes. Appl. Catal. B 2019, 241, 442-451. [CrossRef]

48. Yang, H.; Hu, S.; Zhao, H.; Luo, X.F.; Liu, Y.; Deng, C.F.; Yu, Y.L.; Hu, T.D.; Shan, S.Y.; Zhi, Y.F.; et al. High-performance Fe-doped ZIF-8 adsorbent for capturing tetracycline from aqueous solution. J. Hazard. Mater. 2021, 416, 126046. [CrossRef] 